\title{
Estimating copepod stage-specific mortality rates in open ocean waters: a case study from the northern Gulf of Mexico, USA
}

\author{
Hongsheng Bi ${ }^{1,2, *}$, Kenneth A. Rose ${ }^{1}$, Mark C. Benfield ${ }^{1}$ \\ ${ }^{1}$ Department of Oceanography and Coastal Sciences, Louisiana State University, Baton Rouge, Lousiana 70803, USA \\ ${ }^{2}$ University of Maryland Center for Environmental Science, Chesapeake Biological Laboratory, Solomons, Maryland 20657, USA
}

\begin{abstract}
Knowledge of copepod stage-specific mortality rates is essential for understanding secondary production. A time-series of samples of the calanoid copepod Clausocalanus furcatus was collected from a petroleum platform in the northern Gulf of Mexico every $12 \mathrm{~h}$ for $\sim 2$ to 3 wk in March-April and May-June 2003. Egg and nauplii (stages I and II) abundances were estimated from 301 Niskin water bottle samples, and abundances of later stages were estimated from vertical net tows. An inverse parameter estimation technique based on a stage-based matrix population model and a search procedure using the sequential quadratic programming algorithm was applied to estimate stage-specific mortality rates. Simulation experiments were conducted to test the robustness of this technique. When the technique was applied to simulated data with different levels of variability, introduced by lognormal error terms, the technique performed well at low to medium level of variability (coefficient of variation $<0.5$ ). We then applied this technique to field data in periods when the depth of the pycnocline was similar (i.e. advection was likely similar). The estimated stage-specific mortality rates showed similar patterns across stages in March-April and May-June, with mortality rates being highest for eggs, lower for early nauplii stages, lower still for late nauplii stages, lowest for early copepodite stages, and high again for late copepodite stages. We compare our estimated rates to those reported in the literature and conclude with a discussion of the importance of advancing estimation methods to deal with advection and a recommended approach for applying mortality estimation methods to zooplankton in dynamic environments.
\end{abstract}

KEY WORDS: Copepod - Instantaneous mortality rate $\cdot$ Inverse technique $\cdot$ Matrix population model • Sequential quadratic programming $\cdot$ Sampling variability

Resale or republication not permitted without written consent of the publisher

\section{INTRODUCTION}

Copepods are the most abundant mesozooplankton in pelagic ecosystems (Longhurst 1985), and knowledge of their vital rates is essential for understanding their population dynamics. Small changes in mortality rates can have order of magnitude effects on copepod abundance (Twombly \& Lewis 1989). Temporal and spatial variation in mortality rates, coupled with variation in egg production and developmental rates, largely determine zooplankton species composition and distribution. Mortality rates of copepods often vary among their 13 distinctive life stages, which in turn affect the stage structure and population dynamics (McCauley \& Murdoch 1990, Aksnes et al. 1997).

Estimation of mortality rates from field data is complicated by measurement and biological issues. In the pelagic environment, organisms are often patchily distributed, both vertically and horizontally in the water column, due to behavior and advection (Aksnes et al. 1997), making measurement of their abundance and distribution difficult. Field sampling can be biased towards certain development stages, depending upon gear selectivity (Miller \& Judkins 1981) and how sam- 
pling matches their spatial distribution (Wood \& Nisbet 1991). Biological factors that can influence mortality rates in the field include but are not limited to: predation (Ohman 1986, Steele \& Henderson 1995, Aksnes et al. 1997), cannibalism (Peterson \& Kimmerer 1994, Ohman \& Hirche 2001), food availability (Kleppel et al. 1998), food quality (Ianora et al. 1992, Ianora \& Poulet 1993, Paffenhöfer 2002), and reproductive strategy (Ohman et al. 2002). Moreover, many of these biological processes are influenced by dynamic environmental conditions, and these biological processes can covary in space and time (Hairston \& Twombly 1985, Ohman \& Wood 1996). This further complicates the estimation of mortality rates.

A variety of methods have been proposed for estimating copepod mortality rates. These methods include: life tables (Rigler \& Cooley 1974, Gehers \& Roberston 1975, Manly 1990), vertical life tables (Mullin 1991, Aksnes \& Ohman 1996), and other inverse modeling methods (Hiby \& Mullen 1980, Twombly 1994, Wood 1994). The life table approach depends upon an intensive time series of sampled copepod abundances, while the vertical life table approach can infer mortality rates from snapshot samples (Aksnes et al. 1997). Both life table approaches are relatively simple to apply but require very specific conditions (e.g. closed population) in order for the field data to generate reliable estimates of mortality rates.

The inverse modeling methods have fewer restrictions than the life table approaches, and rely on the fit of a model to measured abundances in order to infer the mortality rates (Wood 1994, Carlotti et al. 2000). Inverse modeling methods can be divided into 2 types based on the model used to fit to the data. Both types assume that changes in stage-specific abundances are governed by growth and mortality rates, but different approaches are taken to fit abundances to development and mortality (Caswell 2001, Wood 1994). Parametric methods (inverse matrix methods) use the stage-based population model itself to do the fitting, whereas semi-parametric methods use a statistical model such as splines (Nelson et al. 2004).

All of the estimation methods require sampling from the same population over time; an assumption that is seldom possible to satisfy for planktonic populations. More often, field data include the effects of timevarying mortality rates caused by changing environmental conditions that are superimposed on variation in abundances caused by other factors such as immigration, emigration, reproductive responses, patchiness, and vertical migration (Huntley \& Niiler 1995, Aksnes \& Ohman 1996). Time-series data of copepod stage abundances are usually obtained from one or more fixed observation points, or from a fixed grid of sampling locations. Estimated abundances are often subject to sampling biases. Over time, differential movement of water column strata can advect individuals in a population in different directions depending upon their depth, leading to a constantly changing population structure at a single Eulerian or Lagrangian station. In such situations, the life table method can generate negative estimates of mortality (Hairston \& Twombly 1985, Caswell 2001). The vertical life table method assumes a steady state, in which recruitment equals mortality for each developmental stage pair (Aksnes \& Ohman 1996). The inverse methods are flexible, but require that data fluctuations be caused by changes in the population's vital rates.

In this study, we sampled a calanoid copepod, Clausocalanus furcatus, from a fixed station in the northern Gulf of Mexico. C. furcatus is an oligotrophic oceanic species, which occurs over a wide latitudinal range $\left(35^{\circ} \mathrm{S}\right.$ to $40^{\circ} \mathrm{N}$ ) (Vervoort 1963, Frost \& Fleminger 1968). It is a common pelagic copepod species in the northern Gulf of Mexico (Bowman 1971, Marum 1974, Minello 1980, Ortner et al. 1989). It carries its eggs within a fragile egg mass (Mazzocchi \& Paffenhöfer 1998), which is often detached from the female abdomen shortly after spawning (Cornils 2005, Bi \& Benfield 2006). We developed a parametric inverse technique to estimate stage-specific mortality rates for $C$. furcatus. We first tested the method using simulated data and then applied the method to the field data. The results of the simulations provided a context for us to better judge the robustness of the estimates based on the field data.

\section{MATERIALS AND METHODS}

Description of the inverse technique. The inverse technique includes the following steps: (1) develop a forward model that can adequately describe the relationship between the stage-specific abundance and mortality rates; (2) set up initial and boundary conditions for the forward model (3) build an objective function that allows the minimization of the difference between the fitted values and the observed values; and (4) implement a nonlinear optimization algorithm to search for the most feasible rates for each stage that minimizes the objective function.

In the present study, copepod abundance of each life stage was recorded as number of individuals per cubic meter (ind. $\mathrm{m}^{-3}$ ) measured at regular $12 \mathrm{~h}$ time intervals. We denote the abundance that begins life stage $j$ at time $t$ as $S_{j, t}$ and the number of these individuals that survive and enter the next stage $12 \mathrm{~h}$ later as $S_{j+1, t+1}$.

Step 1: forward model. Stage-structured matrix projection models have been widely applied to simulate 
zooplankton populations (e.g. Caswell \& Twombly 1989, Torres-Sorando et al. 2003). The population model used here was defined as:

$$
\tilde{S}_{t+1}=T \times \tilde{S}_{t}
$$

where $\tilde{S}_{t}$ is a vector that contains the numbers of individuals for each of 13 stages $\left(S_{j, t}\right)$ at time $t$ and $T$ is the transition matrix. The transition matrix is defined as:

$$
T=\left[\begin{array}{ccccc}
P_{1,1} & 0 & 0 & \cdots & E \\
G_{1,2} & P_{2,2} & \vdots & \vdots & \vdots \\
& G_{2,3} & \ddots & \vdots & \vdots \\
& & \ddots & \ddots & \vdots \\
& & & G_{j, j+1} & P_{j, j}
\end{array}\right]
$$

where $G_{j, j+1}$ is the probability of an individual in the stage $j$ surviving and entering the next stage $j+1$ in the next time step, $P_{j, j}$ is the probability of an individual surviving the stage $j$ and staying in the stage $j$ for the next time step, and $E$ is the reproduction rate (eggs adult $^{-1} 12 \mathrm{~h}^{-1}$ ) for the adult stage. The probability of an individual entering stage $j+1$ from stage $j$ is calculated as the inverse of stage duration for stage $j$ (Caswell 2001). Finite mortality rate $\left(M_{j}\right)$ is related to the elements of the transition matrix by $G_{j, i+1}=\left(1-M_{j}\right) \times 12 /$ $D_{i}$ and $P_{j, j}=1-M_{j}-G_{j, j+1}$. Reproductive rate $E$ and stage development times $\left(D_{i}\right)$ were set to fixed values based on other information, leaving the mortality rates to be estimated in order to determine $G$ and $P$ values.

Step 2: constraints and initial conditions. Egg production rate and stage durations were either derived from laboratory incubations or from field data (see Bi \& Benfield 2006). The incubation experiments were conducted at 24 to $28^{\circ} \mathrm{C}$. We calibrated the stage durations for temperature effects as described in Bi \& Benfield (2006). The stage durations were calibrated to $20^{\circ} \mathrm{C}$ in March-April and $25^{\circ} \mathrm{C}$ in May-June based on fieldmeasured temperature. There are 2 constraints for mortality rates in Eq. (2): finite mortality rates can be neither negative nor larger than 1 .

Step 3: objective function. In the present study, the objective function was to minimize the difference between the fitted abundances from the forward model and the observed stage-specific abundances. We used the sum of the squared differences between the fitted values and the observed data, summed over stages and time, as the objective function:

$$
\begin{aligned}
& f \underset{\min }{f(\tilde{M})}=\sum_{t} \sum_{i}\left(S f_{i, t}-S o_{i, t}\right)^{2} \\
& g_{1}(\tilde{M}) \geq 0 \\
& g_{2}(\tilde{M}) \leq 1
\end{aligned}
$$

where $S f_{i, t}$ is the fitted abundance for stage $i$ at time $t$ from the forward model, $S o_{i, t}$ is the observed abun- dance for stage $i$ at time $t, \tilde{M}$ is a vector of stage-specific finite mortality rates, $g_{1}(\tilde{M})$ is a constraint function, where mortality rates are non-negative values, and $g_{2}(\tilde{M})$ is a constraint function where finite mortality rates are $\leq 1$.

Step 4: search for the best fit mortality rates. The search algorithm uses an iterative technique (sequential quadratic programming) to find the mortality rates that minimize the objective function. The Lagrangian function associated with Eq. (3) can be written as $L(\tilde{M}, \lambda)=f(\tilde{M})+\lambda_{1}^{T} g_{1}(\tilde{M})+\lambda_{2}^{T} g_{2}(\tilde{M})$, where $\lambda=\left(\lambda_{1}, \lambda_{2}\right)$ are the Lagrange multipliers associated with the inequality and equality constraints. If we use $\tilde{M}^{*}$ to denote a vector that holds the best fit finite stage-specific mortality rates, and $\tilde{M}_{0}$ is the initial value, the algorithm will approach $\tilde{M}^{*}$ by defining a step vector $p$, which is a vector of small changes for finite mortality rates. In each iteration, the Lagrange multipliers are estimated and a quadratic subproblem can be formulated.

We can approximate $f(\tilde{M}+p, \lambda)$ using local Taylor expansion:

$$
f(\tilde{M}+p, \lambda) \approx L(\tilde{M}, \lambda)+\nabla L(\tilde{M}, \lambda) \times p+\frac{1}{2} p^{T} \times H \times p^{T}
$$

where $\nabla L(\tilde{M}, \lambda)$ represents the first-order partial derivatives $\frac{\partial L}{\partial \tilde{M}_{k}}$ and $H$ represents the square matrix of second-order partial derivatives, $\frac{\partial^{2} L}{\partial \tilde{M}_{k}^{2}}$ (i.e. the Hess-
ian matrix).

Now, the objective function can be translated into a quadratic programming problem:

$$
\begin{aligned}
& \min \frac{1}{2} p^{T} \times H \times p+\nabla L\left(\tilde{M}_{k}, \lambda\right)^{T} \times p \\
& A_{i} \times p=b_{i} \\
& A_{i} \times p \leq b_{i}
\end{aligned}
$$

where $A_{i}$ refers to the $i$ th row in matrix $A$, which is an estimate of active constraints as described by equality constraints, and $b_{i}$ represents the boundary conditions. Within each iteration, there are 3 steps to solving Eq. (5). First, the Hessian matrix, $H$, is approximated using a quasi-Newton method. Second, we calculate a feasible set of mortality rates and generate an iterative sequence of feasible sets of mortality rates that converge to the solution for Eq. (5). The last step is to produce a vector $p$ and a gradient vector $\alpha$ based on the solution from the previous step. A new set of finite mortality rates, $\tilde{M}_{k+1}$, can now be written as $M_{k}+\alpha \times$ $p_{k}$. The search procedure updates mortality rates and starts another iteration for $\widetilde{M}_{k+1}$ for Eq. (4). In the present study, we used the fmincon procedure with the active set algorithm in Matlab (MathWorks Release 2009b) to estimate the best-fit mortality rates.

Finite mortality rates (i.e. the fraction dying in $12 \mathrm{~h}$ ) were estimated by the inverse method. In the simulation 
experiments, we used finite mortality rates for the convenience of initializing the matrix population model. For the field study, finite mortality rates were converted to instantaneous mortality rates to compare with reported mortality rates from other studies as follows:

$$
1-M_{j}=\mathrm{e}^{-m_{j}}
$$

where $M_{j}$ is the finite mortality rate for stage $j_{\text {, and }} m_{j}$ is the instantaneous mortality rate.

Simulation experiment. In the ocean environment, copepod stage-specific abundances show high variability, thus we wanted to test the robustness of the mortality rate estimation technique before we applied the method to the field data. To examine how the sampling variability influenced mortality estimation, the matrix model was used to generate abundances of life stages over time, but with noise added to the abundances. We then applied the estimation method to the simulated noisy stage abundances, and compared the estimated mortality rates to the known mortality rates used in the matrix model. The simulation experiment was designed to be similar to the field data conditions. The egg production, stage durations, mortality rates, and initial abundances used for the matrix model in the simulation experiment (Table 1) were based on Clausocalanus furcatus, using laboratory and field data described in more detail in Field samples.

The matrix model was used to generate abundances with noise added to the abundance of each of the 13 stages every $12 \mathrm{~h}$ for $20 \mathrm{~d}$. We used a lognormal distribution to generate the noise, because copepods often are patchily distributed in the ocean environment (Wiebe 1970), and a lognormal distribution can resemble skewed and thick-tailed distributions. The simulated abundance of each stage every $12 \mathrm{~h}$ obtained the matrix model was treated as the mean of a lognormal distribution; the standard deviation was then computed from the mean value and specified coefficient of variation $\left(\mathrm{CV}_{i}\right.$ standard deviation/mean). With the mean and standard deviation, actual simulated stage abundance was generated. This was repeated for each of the 13 stages and for each of the $12 \mathrm{~h}$ in the $20 \mathrm{~d}$. For each new time step, the mean abundances were used in the matrix model, rather than the abundances adjusted with noise. We assumed that the noise was associated with patchy distribution and measurement errors. The alternative would have been to use the abundances with noise as the starting point in the matrix to generate the abundances for the next $12 \mathrm{~h}$ (i.e. variability as process error).

We simulated CVs of $0.05,0.1,0.15,0.2,0.25,0.5$, 1.0, and 2.0. CVs estimated from 3 replicate samples for the field data (described in Field samples) were less than 1.0 over all life stages. For each CV, 100 Monte Carlo realizations of stage abundances with noise over the $20 \mathrm{~d}$ were simulated, resulting in 100 estimates of mortality rates for each stage. We show the mean daily abundances of each stage (over the 100 realizations) for the $20 \mathrm{~d}$, and frequency histograms of the 100 realizations of egg stage abundance on Day 5 . We report the mean and standard deviation of the 100 estimates of the mortality rates by stage for each $\mathrm{CV}$. We compare the mean value of the 100 estimates to the known mortality value used in the matrix model.

Field samples. Field sampling was conducted at South Timbalier 151 (ST151), a Chevron offshore petroleum platform complex located $50 \mathrm{~km}$ south of Grand Isle, LA ( $\left.28^{\circ} 37^{\prime} \mathrm{N}, 90^{\circ} 15^{\prime} \mathrm{W}\right)$ in $45 \mathrm{~m}$ deep water (Fig. 1). Zooplankton were collected in 2003 at $12 \mathrm{~h}$ intervals from 18 March to 6 April and then from 15 May to 9 June using a 301 Niskin bottle and a $70 \mathrm{~cm}$ diameter ring plankton net (2.5 m long, $153 \mu \mathrm{m}$ mesh). Niskin bottles were deployed at depths of 5, 15, and $25 \mathrm{~m}$, and the contents were filtered through $20 \mu \mathrm{m}$ mesh. Each sampling event consisted of 3 replicate water bottle samples from each depth. Vertical net tows were made in the depth range 0 to $15 \mathrm{~m}$ because of the presence of a subsea platform cross-member at $\sim 20 \mathrm{~m}$. A mechanical flow meter (2030, General Oceanics) was attached to the mouth of the net to measure the filter volume, and the net was hauled to the surface at a retrieval rate of 20 to $25 \mathrm{~cm} \mathrm{~s}^{-1}$ using an electric winch. Each net sample also consisted of 3 replicate net tows collected within $30 \mathrm{~min}$. The average water volume filtered for each net tow was $5.75 \mathrm{~m}^{3}$. Samples were fixed in $5 \%$ formalin and transferred to $70 \%$ ethanol in the lab before being sorted and identified.

Table 1. Clausocalanus furcatus. Egg production, stage durations, mortality rates, and initial abundances used in the simulation experiments. Egg production and development times were measured in laboratory experiments (Bi \& Benfield 2006). The mortality rates reflect possible stage schedules of mortality that have been reported in the literature. Initial conditions were estimated from 3 replicated net samples on the first sampling time (March 18,2003) as part of the field study. $\mathrm{N}=$ nauplii, $\mathrm{C}=$ copepodite, $\mathrm{AD}=\mathrm{adult}$

\begin{tabular}{|c|c|c|c|c|c|c|c|c|c|c|c|c|c|}
\hline Stage & Egg & NI & NII & NIII & NIV & NV & NVI & $\mathrm{CI}$ & CII & CIII & CIV & $\mathrm{CV}$ & $\mathrm{AD}$ \\
\hline Egg production (eggs adult ${ }^{-1} 12 \mathrm{~h}^{-1}$ ) & - & - & - & - & - & - & - & - & - & - & - & - & 1.33 \\
\hline Duration $(\mathrm{h})$ & 8 & 17 & 14 & 17 & 28 & 29 & 20 & 33 & 33 & 42 & 29 & 96 & \\
\hline Mortality $\left(\% 12 \mathrm{~h}^{-1}\right)$ & 50 & 20 & 20 & 30 & 30 & 20 & 20 & 10 & 10 & 10 & 10 & 20 & 20 \\
\hline Initial abundances (ind. $\mathrm{m}^{-3}$ ) & 155 & 44 & 51 & 36 & 44 & 14 & 214 & 73 & 207 & 251 & 221 & 325 & 177 \\
\hline
\end{tabular}




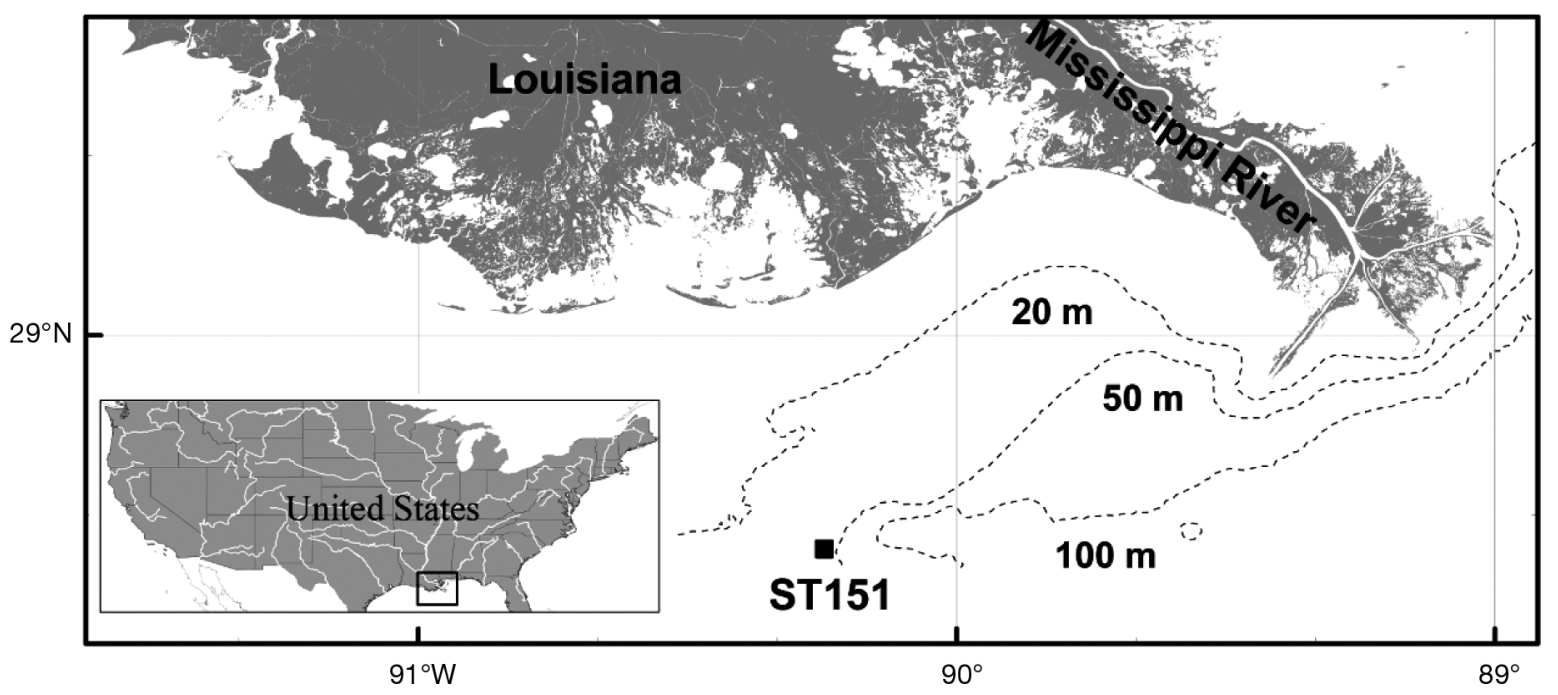

Fig. 1. Location of the South Timbalier 151 (ST151) study site in relation to the Mississippi River delta, with 3 depth contours indicated

To identify eggs and other developmental stages for Clausocalanus furcatus, we conducted series of incubation experiments, and then incubated individuals were used as reference specimens to distinguish eggs, nauplii and copepodites belonging to $C$. furcatus under a stereo microscope $(\times 50)$. All stage abundances were reported as number of individuals per cubic meter (ind. $\mathrm{m}^{-3}$ ), and the $\mathrm{CV}$ was calculated for each sample using the 3 replicate values. Further details about the sampling and additional analyses concerning $C$. furcatus and zooplankton community dynamics can be found in Bi (2005) and Bi \& Benfield (2006). We focus on the measured stage abundances of $C$. furcatus in this paper. Although the net samples were collected from the upper $15 \mathrm{~m}$, the estimated abundance for the adult stage from the present study ranged from 44 to 870 ind. $\mathrm{m}^{-3}$ with an average of $257 \pm 137$ ind. $\mathrm{m}^{-3}$ in March-April and $299 \pm 183$ ind $\mathrm{m}^{-3}$ in May-June, which was consistent with results from other studies in the Gulf (Marum 1974, Minello 1980, Lester et al. 2008).

The described inverse technique was applied to the field samples collected in March-April and May-June 2003, whenever the sampling interval was "12 h. We used Niskin water bottle samples to estimate abundances for stages from egg to nauplii II and net samples for stages from nauplii III to adult, because net samples consistently had higher abundances than Niskin water bottle samples starting from nauplii V and slightly higher abundances for nauplii III and IV. We grouped samples into 7 time periods (3 during March-April and 4 during May-June) based on salinity profiles measured with each sample (Table 2 ). The 7 periods corresponded to the pycnocline remaining at similar depths among samples. Consistent pycnocline depths should indicate a relatively stable physical environment and a period when advection should be similar. We obtained 7 sets of stage-specific mortality rates, one for each time period. We show the fit of the matrix model-generated stage abundances for each period, plotted with measured abundances, and report the sum of squared residuals associated with each time period. We also averaged the mortality rates over the periods April-May and June-July, and compared the averaged values to values reported in the literature.

\section{RESULTS}

\section{Simulation experiment}

Total population abundance declined over the $20 \mathrm{~d}$ simulation period for all CV values (Fig. 2). As expected, stage abundances showed increasing variation with increasing $C V$, with large variations gener-

Table 2. Summary of periods when the depth of the 31-isohaline remained similar and the number of samples collected in each period with number of replicates listed in parentheses

\begin{tabular}{|lccc|}
\hline Dates & $\begin{array}{c}\text { Depth of } \\
\text { 31-iso- } \\
\text { haline (m) }\end{array}$ & $\begin{array}{c}\text { Mean } \\
\text { temperature } \\
\text { at 10 m }\left({ }^{\circ} \mathrm{C}\right)\end{array}$ & $\begin{array}{c}\text { Number } \\
\text { of } \\
\text { samples }\end{array}$ \\
\hline March 19-21 & 0 & 20.58 & $6 \times(3)$ \\
March 23-27 & $\sim 5-6$ & 20.26 & $8 \times(3)$ \\
April 2-4 & $\sim 7-8$ & 19.99 & $6 \times(3)$ \\
May 16-19 & $\sim 1$ & 25.21 & $8 \times(3)$ \\
May 20-23 & $\sim 5-6$ & 26.13 & $7 \times(3)$ \\
May 23-26 & $\sim 1$ & 25.54 & $7 \times(3)$ \\
June 2-6 & $\sim 6-7$ & 26.30 & $9 \times(3)$ \\
\hline
\end{tabular}



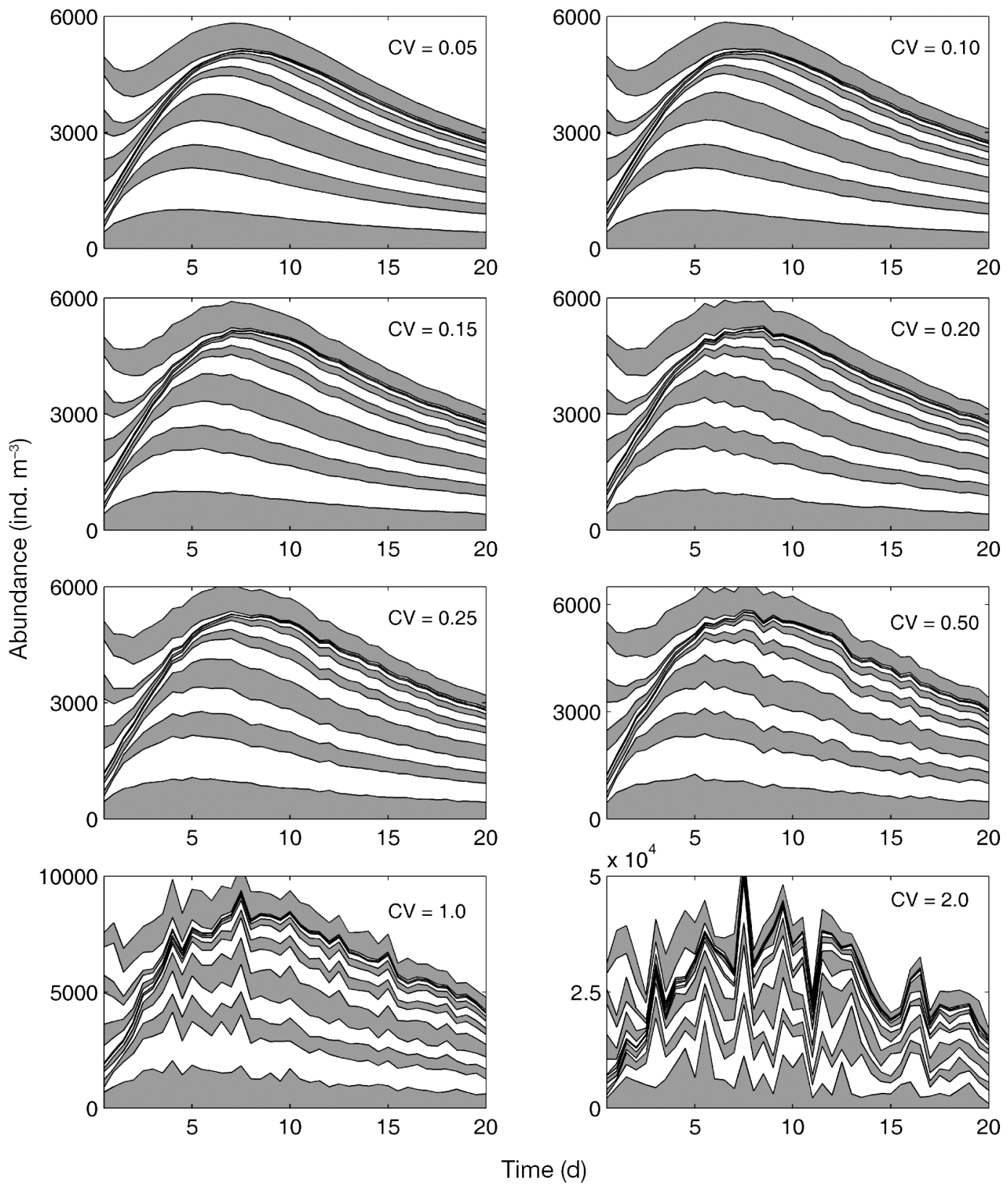

Fig. 2. Clausocalanus furcatus. Simulated mean abundance (for each development stage, number of individuals $\mathrm{m}^{-3}$ ) under different levels of variability generated from lognormal distributions. The level of variability was indicated by the coefficient of variation (CV). The mean stage abundances are from 100 Monte Carlo realizations at each CV level. Shading between lines visually separates different developmental stages, with alternating shaded and white areas indicating egg (bottom in each panel), nauplii I to VI, copepodite I to V, and adult stage (top shade area in each panel)

ated for $\mathrm{CV}=1.0$ and 2.0. The increase in variation with increasing $\mathrm{CV}$ was seen as increasing fluctuation of the mean values (Fig. 2). Egg abundances on Day 5 were between 650 and $1000 \mathrm{~m}^{-3}$ with modes approximately in the middle of the range for CVs of 0.5 and smaller (Fig. 3). For CV $=1.0$ and 2.0, egg abundances on Day 5 showed much wider ranges (800 to 2000 and 0 to $30000 \mathrm{~m}^{-3}$ ) and modes clearly skewed to the left (Fig. 3).
Estimated mortality rates were very similar to the known (preset) values for CVs of 0.05 and 0.1 , and progressively diverged from the preset values with increasing CV (Fig. 4). When CV was high, the estimated mortality rates were consistently higher than the preset values. The overestimation was largely caused by the large deviation from the baseline population (Figs. 2 \& 3 ), which often required mortality rates to be negative to compensate for the deviation, but mortality rates 

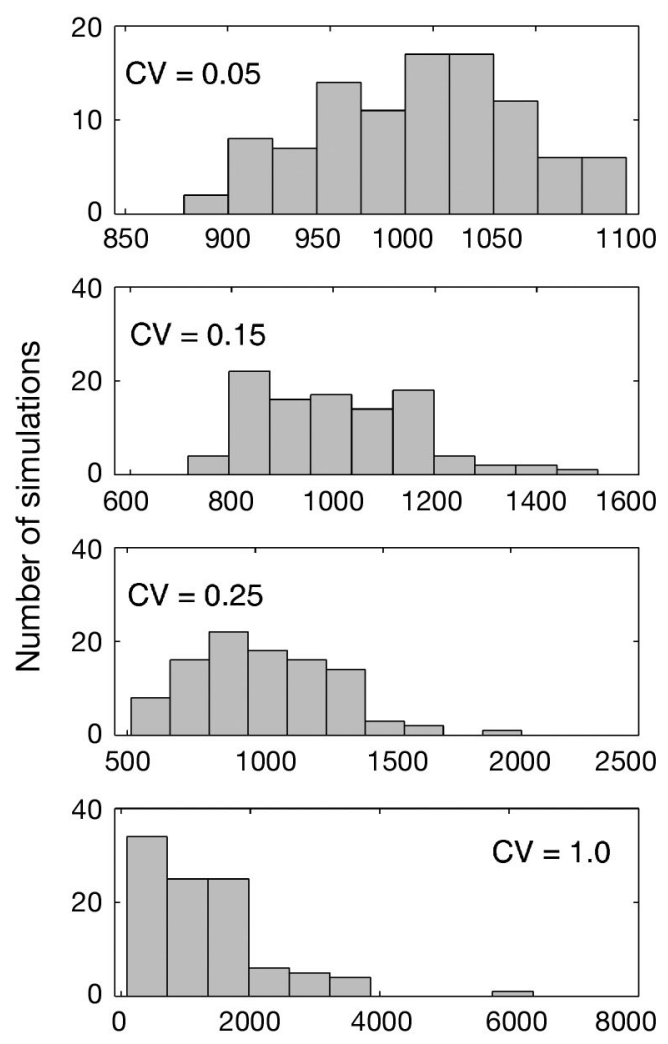
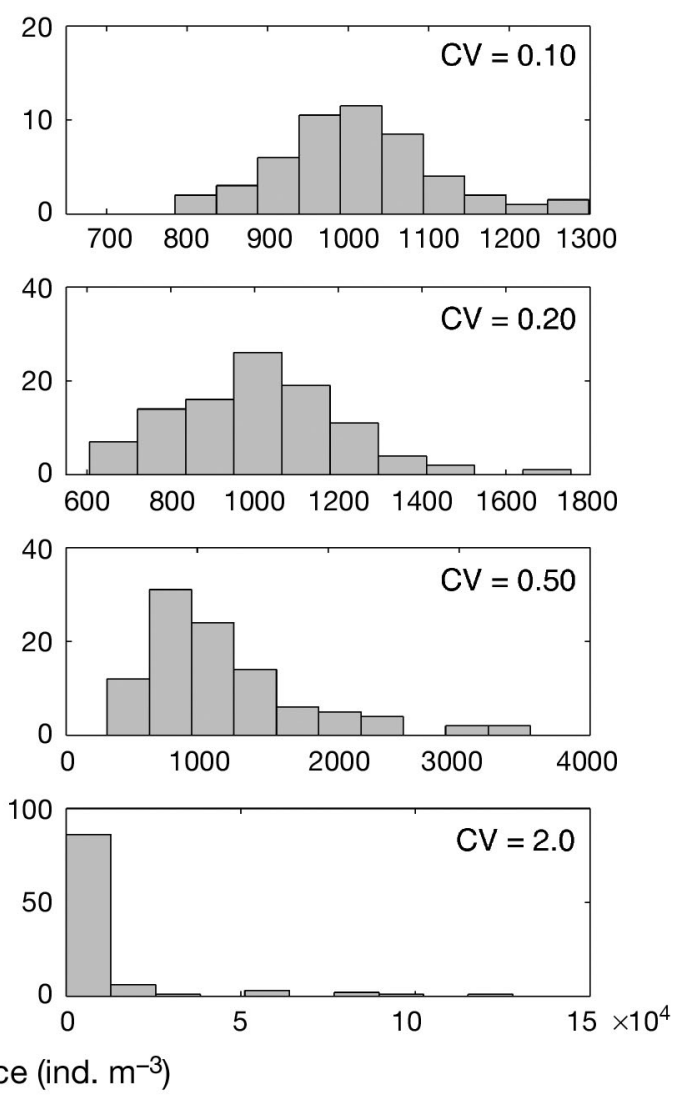

Fig. 3. Clausocalanus furcatus. Simulated egg abundances on Day 5 for each CV. The frequency histograms are based on the 100 values generated from lognormal distributions

were constrained to be positive values in the present study. For $\mathrm{CV}=0.05$, the percentage differences $(100 \times$ (preset - estimated) $\div$ preset) averaged $3 \%$ (maximum of $5 \%$ ) across life stages, except for nauplii IV (averaged $13 \%$ ) and copepodite I (averaged 15\%). For CV = 0.10 , the percentage differences averaged $10 \%$ across life stages, except nauplii IV (60\%), copepodite I (50\%), and adult (21\%). Percentage differences averaged 15\% for $\mathrm{CV}=0.15,27 \%$ for $\mathrm{CV}=0.2$, and $36 \%$ for $\mathrm{CV}=0.25$. Finally, percentage differences exceeded $100 \%$ for CVs of 0.5 and larger $(113 \%$ for $\mathrm{CV}=0.5,300 \%$ for CV $=1.0$, and $507 \%$ for $\mathrm{CV}=2.0$ ).

\section{Field data: physical conditions}

The study site ST151 is located in a region that is frequently influenced by the Mississippi River plume (Fig. 1). During 2 periods, consistent plume water occurred at the study site (March 23 to March 26 and May 30 to June 9). The 31-isohaline generally captured the plume events. The depth of the 31-isohaline ranged from 0 to $12.5 \mathrm{~m}$ (mean of $4.43 \pm 2.96 \mathrm{~m}$ ) (Fig. 5). There were 7 time periods during which depths of the 31-isohaline were somewhat similar (Table 2). Surface water temperature ranged from $\sim 19$ to $24.7^{\circ} \mathrm{C}$ in March-April and gradually increased to $28^{\circ} \mathrm{C}$ in May-June.

\section{Field data: stage-specific abundances}

The mean stage-specific abundances showed relatively large variation ranging from 96 to 543 ind. $\mathrm{m}^{-3}$ in March-April and from 6 to 366 ind. $\mathrm{m}^{-3}$ in May-June, with the highest abundances in both study periods recorded for copepodite III and the lowest abundances recorded for nauplii I (Tables 3 \& 4). Although abundances were higher in May-June across all stages, there were no clear cohorts in either the March-April or May-June periods (Fig. 6). Egg and nauplii stages had higher abundances in March-April than in May-June, when nauplii abundances were mostly lower than 100 ind. $\mathrm{m}^{-3}$. Copepodite stages had higher abundances than nauplii stages and eggs in both study periods. Eggs had higher abundances than nauplii stages in March-April but not in May-June. The CV at each sampling interval ranged from 0 to 3.7, with 

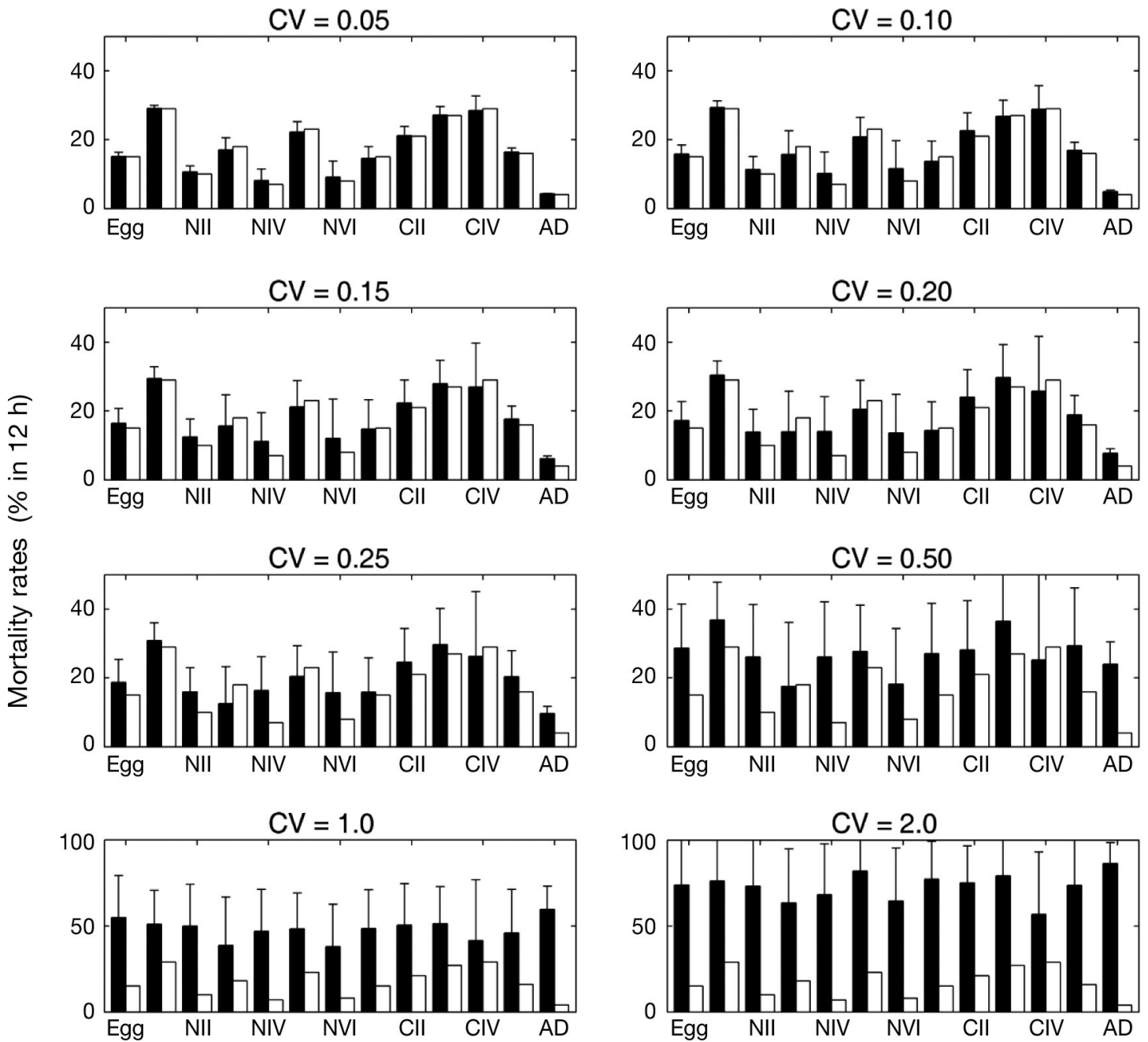

Stages

Fig. 4. Clausocalanus furcatus. Estimated stage-specific mortality rates for populations with different levels of coefficients of variation (CV). White bars: preset mortality rates used in the matrix projection model to generate the stage abundances; black bars: mortality rates estimated from the stage-specific abundances. $\mathrm{N}=$ nauplii, $\mathrm{C}=$ copepodite $, \mathrm{AD}=\mathrm{adult}, \mathrm{AD}=\mathrm{adult}$

Table 3. Clausocalanus furcatus. Stage-specific abundances at Stn ST151. The abundances of eggs and nauplii stages I and II were calculated from Niskin bottle samples from 5, 15, and $25 \mathrm{~m}$ depths, with 3 replicates for each depth. The abundances of nauplii stages III to VI and copepodite stages were estimated from vertical net samples from 0 to $15 \mathrm{~m}$. All stage abundances are reported as number of individuals $\mathrm{m}^{-3} . \mathrm{N}=$ nauplii, $\mathrm{C}=$ copepodite, $\mathrm{AD}=$ adult

\begin{tabular}{|c|c|c|c|c|c|c|c|c|c|c|c|c|c|c|}
\hline & & Egg & NI & NII & NIII & NIV & NV & NVI & $\mathrm{CI}$ & CII & CIII & CIV & $\mathrm{CV}$ & $\mathrm{AD}$ \\
\hline \multirow[t]{4}{*}{ March-April } & Mean & 268 & 96 & 166 & 240 & 145 & 116 & 141 & 241 & 540 & 543 & 511 & 527 & 267 \\
\hline & Standard deviation & 233 & 102 & 233 & 368 & 126 & 74 & 114 & 152 & 330 & 265 & 184 & 236 & 145 \\
\hline & Minimum & 15 & 0 & 7 & 15 & 11 & 15 & 7 & 81 & 122 & 148 & 170 & 170 & 44 \\
\hline & Maximum & 833 & 411 & 872 & 1582 & 584 & 258 & 422 & 710 & 1701 & 1553 & 843 & 887 & 562 \\
\hline \multirow[t]{4}{*}{ May-June } & Mean & 36 & 6 & 46 & 34 & 20 & 19 & 12 & 129 & 271 & 366 & 322 & 331 & 299 \\
\hline & Standard deviation & 90 & 12 & 59 & 43 & 28 & 23 & 15 & 149 & 208 & 196 & 187 & 230 & 183 \\
\hline & Minimum & 0 & 0 & 0 & 0 & 0 & 0 & 0 & 0 & 0 & 70 & 30 & 70 & 70 \\
\hline & Maximum & 429 & 67 & 251 & 170 & 133 & 89 & 63 & 755 & 1193 & 1017 & 843 & 1131 & 876 \\
\hline
\end{tabular}


Table 4. Clausocalanus furcatus. Stage-specific mortality rates and sum of squared residuals (SSR) at Stn ST151 during the period that the depths of the 31-isohaline were similar. All stage-specific mortality rates were reported as \% per $12 \mathrm{~h}$ time frame. $\mathrm{N}=$ nauplii, $\mathrm{C}=$ copepodite, $\mathrm{AD}=$ adult

\begin{tabular}{|lcccccccccccccc|}
\hline Date & Egg & NI & NII & NIII & NIV & NV & NVI & CI & CII & CIII & CIV & CV & AD & SSR $\left(10^{6}\right)$ \\
\hline March 19-21 & 0.59 & 0.00 & 0.71 & 0.67 & 0.00 & 0.61 & 0.00 & 0.00 & 0.00 & 0.00 & 0.00 & 0.45 & 0.33 & 2.0 \\
March 23-27 & 0.66 & 0.00 & 0.00 & 0.37 & 0.79 & 0.00 & 0.28 & 0.00 & 0.00 & 0.28 & 0.24 & 0.52 & 0.23 & 7.5 \\
April 2-4 & 0.87 & 0.60 & 0.17 & 0.00 & 0.00 & 0.00 & 0.43 & 0.00 & 0.00 & 0.00 & 0.00 & 0.06 & 0.00 & 2.3 \\
May 16-19 & 0.92 & 0.00 & 0.73 & 0.99 & 0.50 & 0.99 & 1.00 & 0.37 & 0.00 & 0.00 & 0.00 & 0.09 & 0.14 & 1.2 \\
May 20-23 & 0.78 & 0.27 & 0.00 & 0.03 & 1.00 & 0.13 & 0.00 & 0.56 & 0.00 & 0.16 & 0.00 & 0.32 & 0.22 & 1.3 \\
May 23-26 & 1.00 & 0.34 & 1.00 & 0.20 & 1.00 & 0.13 & 0.00 & 0.56 & 0.00 & 0.16 & 0.00 & 0.32 & 0.22 & 1.3 \\
June 2-6 & 0.86 & 0.67 & 0.92 & 0.68 & 0.62 & 0.00 & 0.00 & 0.17 & 0.13 & 0.34 & 0.24 & 0.45 & 0.33 & 2.3 \\
\hline
\end{tabular}

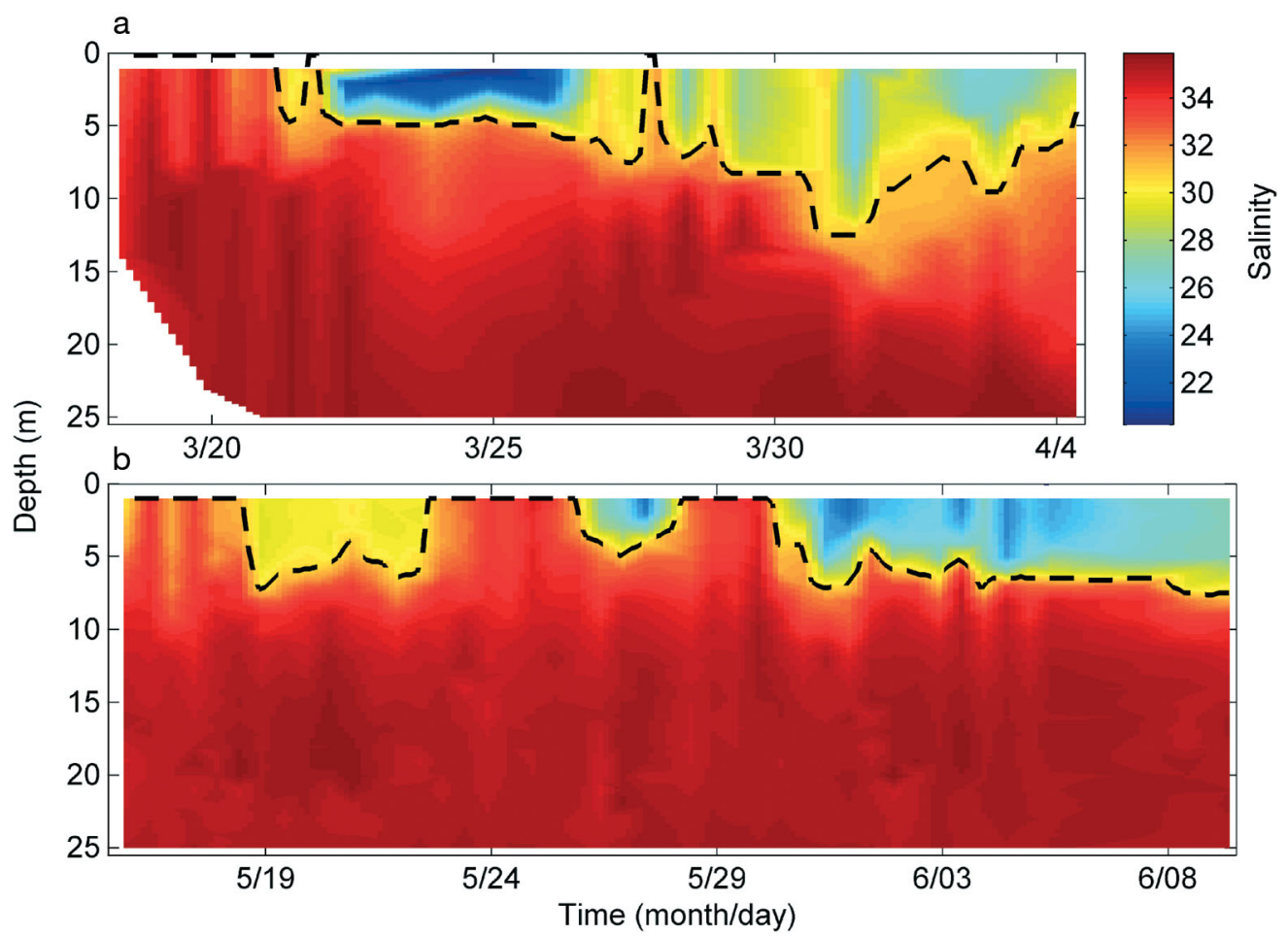

Fig. 5. Salinity profile during (a) March-April and (b) May-June. Dashed lines indicate the 31-isohaline

$90 \%$ of the CV values less than 0.8 and $54 \%$ of the values less than 0.5 . The copepodite stages generally had larger CVs than nauplii stages (Fig. 6).

\section{Field data: estimated mortality rates}

Stage-specific mortality rates were highly variable across all stages in both study periods with relatively larger variability in May-June than March-April (Fig. 7). Mortality rates for egg and nauplii stages showed larger variation than those for copepodite stages (Table 4). When the estimated mortality rates were substituted back into the matrix model and the 7 periods were simulated, the rates resulted in good fits to the observed values (solid line in Fig. 6). The sum of squared residuals between predicted and observed stage abundances, summed over measurements within each of the 7 time periods and over all stages, ranged from $1.2 \times 10^{6}$ to $7.5 \times 10^{6}$ (Table 4 ). When standardized by the number of samples, the sum of squared residuals was generally lower in May-June than MarchApril.

The mean instantaneous mortality rate for eggs was $2.48 \mathrm{~d}^{-1}$ in March-April and $4.36 \mathrm{~d}^{-1}$ in May-June. The mean instantaneous mortality rates for nauplii stages in March-April ranged from 0.44 to $0.85 \mathrm{~d}^{-1}$ with the highest for nauplii III followed by nauplii II (Fig. 7). In May-June, the mean instantaneous mortality rates for naupllii were higher than in 

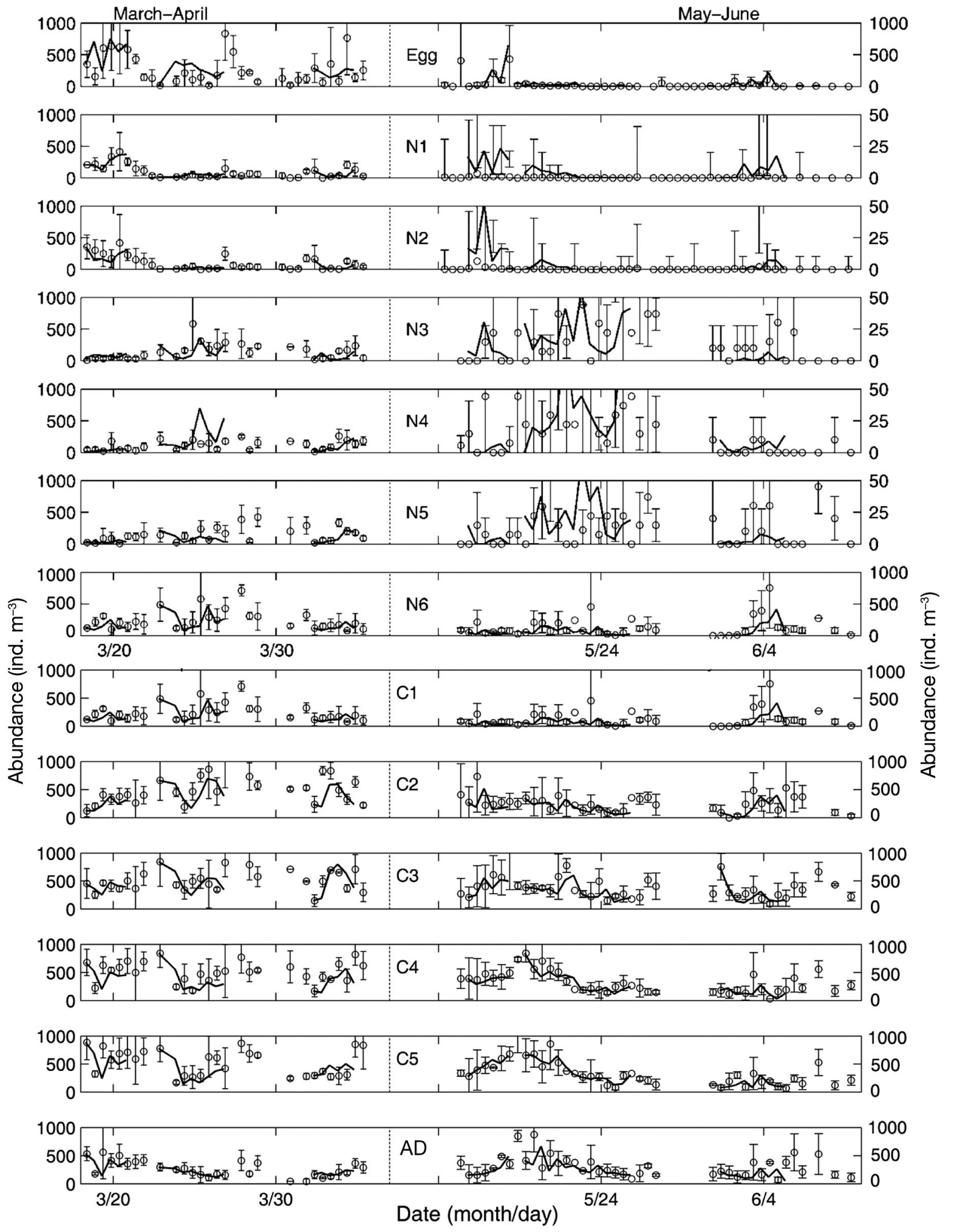

Fig. 6. Clausocalanus furcatus. Measured (circles) and predicted (solid line) stage-specific abundances at the study site during the March-April and May-June time periods. Measured egg, nauplii I (NI) and NII data were collected from 5, 15, and 25 m depths using a Niskin bottle and 3 replicates at each depth stratum. NIII to VI, copepodite stages I to V and adults (AD) were collected with a $153 \mu \mathrm{m}$ mesh net from $15 \mathrm{~m}$ water depth to the surface with 3 vertical net tows. Predicted values are from 7 time periods (Table 2) and are derived from the stage-based model using the best-fit mortality rates. Error bars represent 1 standard deviation 
March-April, ranging from 0.58 to $3.03 \mathrm{~d}^{-1}$ with the highest for nauplii IV followed by nauplii II and III. The mean instantaneous mortality rates for copepodite stages were lower than eggs and nauplii stages, ranging from 0 to $0.84 \mathrm{~d}^{-1}$ in March-April and 0.12 to $0.79 \mathrm{~d}^{-1}$ in May-June. The adult stage and copepodite $\mathrm{V}$ had relatively high mortality rates compared to other copepodite stages in both study periods. The mean instantaneous mortality patterns across developmental stages were similar in the 2 study periods: highest rates in eggs, intermediate rates that decreased from early to late nauplii stages, and consistently low rates for early copepodites that increased for the 2 latest copepodite stages.

\section{DISCUSSION}

\section{Performance of the methods}

Our parametric estimation method generally performed well for simulated populations using stage abundances with lognormal error terms when the CV was 0.5 or less. In the present study, CVs of stage abundances measured in our field data were typically about 0.5 based on 3 replicate net samples. Thus, we have some confidence in the mortality rates we estimated from the field data. Increasing the sample size to 5 replicate samples in future field sampling, which should lower the field-based CVs below 0.5, would increase our confidence in the estimated mortality rates even further. When we examined the predicted stage abundances corresponding to the estimated mortality rates, the fitted values of stagespecific abundances were consistent with the observed stage-specific abundances and most of them $(98 \%)$ fell within the range of observed abundance \pm 1 standard deviation (Fig. 6). Our estimation approach seems promising for generating robust stage-specific mortality rates for copepods in dynamic environments.

In addition to being robust, our mortality estimation method is also flexible. The method we implemented in this study is essentially a model-independent technique. The search algorithm can be combined with any structured population model (e.g. we used a 13 stage model) to estimate mortality rates. The matrix projection model that forms the basis of our method can be easily written as a set of linear equations that can be tailored to the form of the available data. For example, if only copepodite V and VI abundances are available, then a single equation can be written for both stages combined. Our method can be implemented using a variety of readily available software packages (e.g. we used the fmincon functions in Matlab).

\section{Estimated mortality rates for Clausocalanus furcatus and potential sampling issue}

The estimated mortality rates for the field data showed maximum values for the early and late stages, and were similar between the March-April and MayJune periods (Table 4, Fig. 7). Eggs had the highest mortality rates $\left(2.48 \mathrm{~d}^{-1}\right.$ in March-April and $4.37 \mathrm{~d}^{-1}$ in May-June), rates then dropped for early nauplii stages (0.45 to $3.03 \mathrm{~d}^{-1}$ for nauplii I to IV), were even lower for late nauplii stages $\left(0.45\right.$ to $0.76 \mathrm{~d}^{-1}$ for nauplii $\mathrm{V}$ and $\mathrm{VI})$, lowest for early copepodite stages $\left(0\right.$ to $0.64 \mathrm{~d}^{-1}$ for stage I to IV), and high again for late copepodite stages ( 0.41 to $0.84 \mathrm{~d}^{-1}$ for stage $\mathrm{V}$ and adults). In the MarchApril study period, $2 \%$ of the eggs would survive to enter the adult stage, whereas in the May-June study period $<1 \%$ eggs would survive to enter the adult stage. Nauplii III or IV is the initial feeding stage, which is coincident with relatively high mortality rates. In both study periods, mortality rates showed large variation across stages. This variation could be related to difference in potential predators, degree of patchiness, difference among stages in the effects of advective and other mixing processes, and biases in the sampling.

The key question is whether our mortality rate estimates for Clausocalanus furcatus are reasonable. We believe that they are reasonable for 3 reasons. First, the consistency between the fitted and observed stage abundances was high. Second, the performance of our approach with simulated data that included noise was good for a CV value of 0.50 , which was the typical CV observed in the field samples. When the CV increased to 1 , the performance started to deteriorate. Finally, the estimated mortality rates were consistent with mortality rates reported in other studies. Kiørboe (1997) summarized studies before 1997, and Table 5 shows rates reported in some recent studies. Estimated mortality rates from different studies vary by up to 1 order of magnitude. Despite the variation, our estimates were consistent with the reported rates. Both our rates and reported rates were generally high for eggs (typically $>1.35$ for several published studies), intermediate for nauplii and copepodite stages $\left(0\right.$ to $0.34 \mathrm{~d}^{-1}$ in the literature), and high again for copepodite $\mathrm{V}$ and adults. For example, Ohman et al. (2004) found a high instantaneous mortality rate in eggs $\left(1.78 \mathrm{~d}^{-1}\right)$ and very low mortality rates for stages from nauplii II to copepodite IV at a North Sea station (oceanic), and a Lurfjorden station in the Norwegian Sea (coastal). Eiane et al. (2002) and Eiane \& Ohman (2004) also reported similar mortality patterns for Calanus finmarchicus, Oithona similis, and Calanus spp.

The relatively high adult stage mortality rates estimated in this study might be associated with predation 


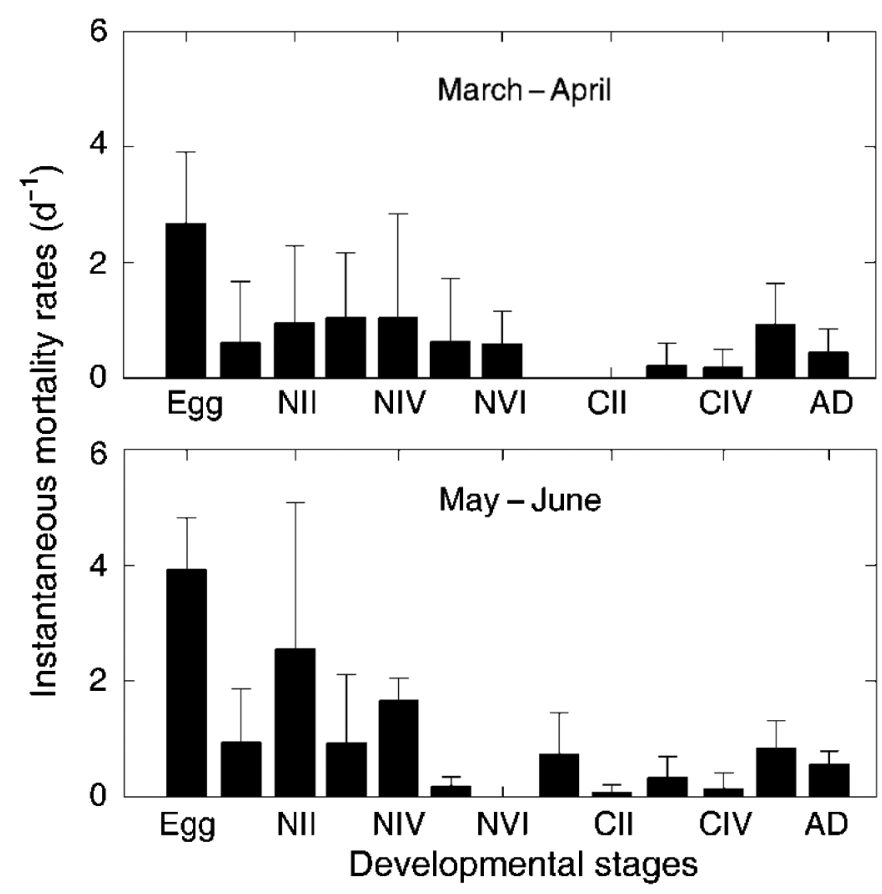

Fig. 7. Clausocalanus furcatus. Estimated instantaneous stage-specific mortality rates (number of individuals per day) for March-April (top) and May-June (bottom). Mortality rates were averaged by life stage from the 3 time periods within March-April and for the 4 periods within May-June. Error bars represent 1 standard deviation. $\mathrm{N}=$ nauplii, $\mathrm{C}=$ copepodite, $\mathrm{AD}=$ adult

from higher trophic levels or be related to gender. Fish densities including planktivorous fish like the blue runner Caranx crysos are elevated around offshore petroleum platforms relative to the open waters in the Gulf of Mexico (Rountree 1990, Stanley \& Wilson 1990, Love et al. 1999, Keenan 2002). Adult mortality may also have been high due to differential gender-specific mortality. Adult males were much less abundant than adult females in the field samples.

One common assumption of all mortality estimation techniques is that samples were taken from the same population. However, this assumption is unlikely to be met due to advection (Aksnes \& Magnesen 1983, Herman et al. 1991) and the patchy distribution of plankton (Aksnes et al. 1997). As part of the simulation analysis with known mortality rates, we also simulated uniform advection across stages (results not shown). The estimated mortality rates simply were increased above the preset values by the advection rate (i.e. the estimation method treated advection as mortality). In the present study, field samples were collected from a fixed location within an area under the influence of the Mississippi River plume (Bi 2005, Bi \& Benfield 2006). Location of sampling (within or outside of the plume) would result in high variability due to the dynamic environmental conditions between the 2 water masses (Dagg \& Whitledge 1991). Ultimately, this raises the issue of what constitutes the spatio-temporal boundary of a population and whether or not samples collected from a fixed (Eulerian) station, or even a moving (Lagrangian) station, are sufficiently representative. In the former case, our petroleum platform might be viewed as a randomly-located point within a region containing a population of Clausocalanus furcatus that is constantly changing in terms of stage abundance due to the effects of advection. A Lagrangian station would not likely improve the situation, because it would have to move with the water without shear, and the water would have to move as a uniform slab. Both of these assumptions are not realistic. Here, we applied the estimation method separately to periods within which the depth of the pycnocline (approximated at the 31-isohaline) was similar to try to minimize advection effects.

The short interval between samples (12 h) made it possible to take repeated samples within a patch and then apply the matrix projection model to estimate mortality within each of the patches. However, sampling bias, a long recognized problem for estimating copepod stage-specific abundances, was a challenge. We used a $153 \mu \mathrm{m}$ zooplankton net (filtered volume $\sim 5.75 \mathrm{~m}^{3}$ ) along with a 301 Niskin water bottle (filtered volume $0.27 \mathrm{~m}^{3}, 3$ depth strata with 3 replicates) to estimate the stage-specific abundances. Escapement through the net meshes might be a problem for early nauplii stages (I and II), and the Niskin bottles may not provide adequate sampling volume for later stages. Meanwhile, clogging is a potential problem for net with finer mesh, because the study site was located in a highly productive region near the Mississippi River plume. In the present study, net samples generally yielded higher estimates for later nauplii stages when compared to Niskin bottle samples except for nauplii stage VI in May- June. The ratios between net samples and Niskin bottle samples for nauplii III to VI (stage indicated in parentheses) were: $9.12 \pm 13.29$ (III), $3.76 \pm$ 4.19 (IV), $3.66 \pm 3.92$ (V), $3.32 \pm 3.31$ (VI) in March-April and $3.63 \pm 3.70$ (III), $2.20 \pm 4.33$ (IV), $1.23 \pm 2.59(\mathrm{~V}), 0.45 \pm 0.82(\mathrm{VI})$ in May-June. Improvements in sampling techniques for early nauplii stages are necessary to properly estimate their mortality rates.

\section{Recommendations and further study}

This study underscores the widely held opinion that estimating copepod stage-specific mortality rates can be difficult, especially with high sampling variability. It 


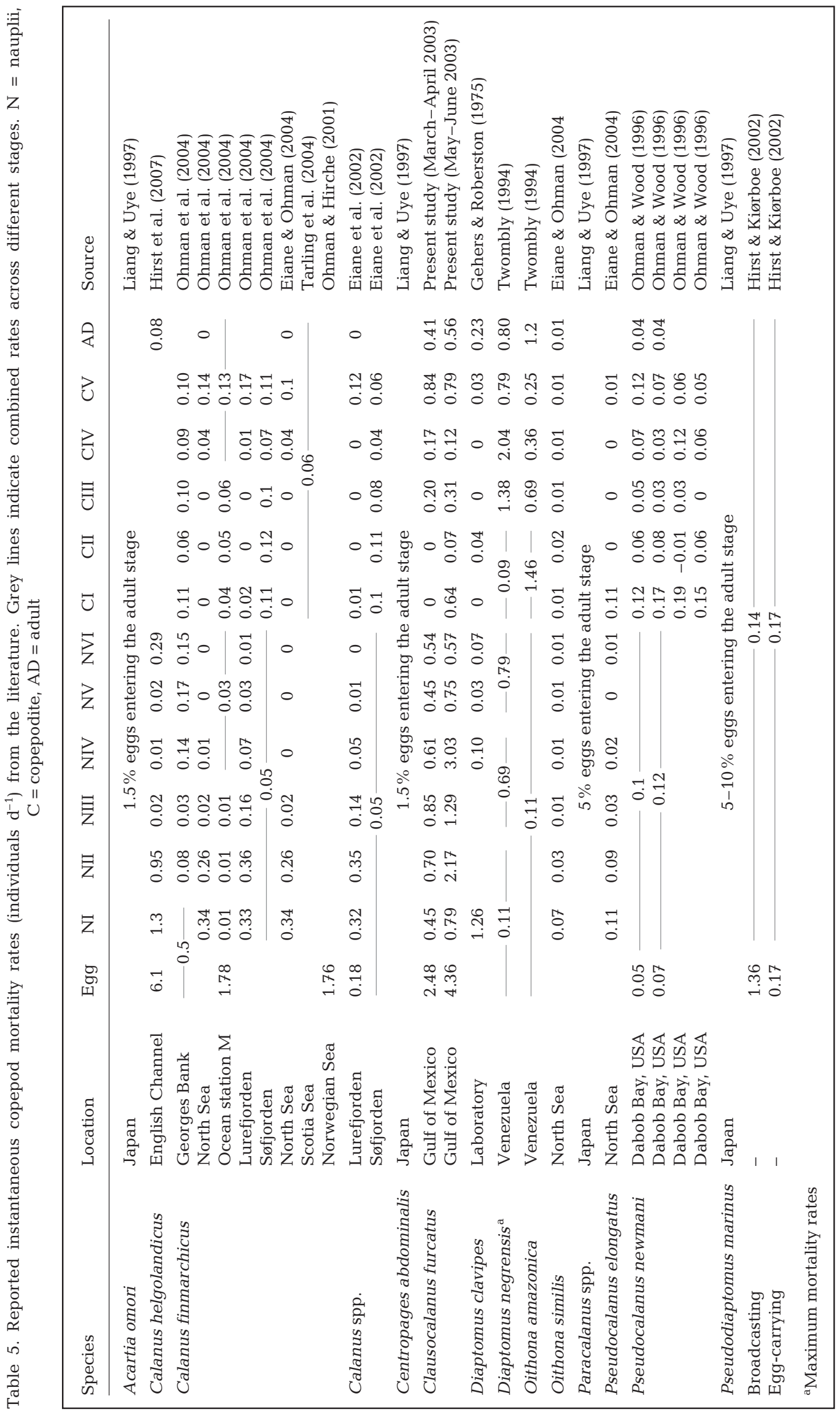


was reassuring that our parametric inverse technique was able to recover known mortality rates in the simulated population under conditions of similar levels of variability as observed in the field samples. We have explored other estimation methods, and variations on the method used here, to try to deal with advection effects explicitly, but with limited success. Development of estimation methods that can separate advection from mortality would improve mortality estimation. Until these methods are developed and evaluated, we recommend subsetting the field data into relatively homogenous periods, as was done in this analysis. This subsetting, coupled with simulation analysis of the effects of measurement variability under conditions similar to field conditions, should lead to realistic and robust estimation of mortality rates.

Estimating stage-specific morality rates of copepods is critical for understanding and modeling their population dynamics. This has been a long-term problem, and yet complete resolution continues to evade us. New variations on the general inverse approach continue to be proposed. For example, Gilioli \& Pasquali (2007) recently suggested linking individual and stage-based models, and using the individual-based model to estimate time-dependent reproduction. The 2 models would then be solved iteratively to ultimately estimate stage-specific mortality rates.

We suggest that further analyses focus on: (1) conducting detailed comparison with other existing techniques such as life table methods and the surface smooth method (Wood 1994); (2) exploring ways to explicitly incorporate auxiliary information (e.g. advection) into the inverse methods using more complicated models (Li et al. 2006); and (3) assessing the sensitivity of this inverse method to assuming an incorrect model for the underlying population dynamics. We simulated a simple case of noise in abundances that put variability on the simulated abundances at each time step for each developmental stage. Other ways to incorporate noise would have been to generate deviations and to maintain serial correlation among the realized abundances (e.g. random walk of stage abundances through time). This would have simulated process error, rather than measurement error. Expanding the population dynamics models that underlie the inverse methods to include temperature, food, predation, and advective effects should help the accuracy of mortality rates estimated from field data. Complete resolution of this problem may be difficult until fundamentally new types of field data (e.g. cohort identification) are available. In the meantime, we recommend subsetting the data into homogenous periods, applying a variety of methods, and including simulation analysis under realistic variability in order to obtain realistic mortality rates.
Acknowledgements. This research was funded by the State of Louisiana. We thank Chevron and the crew on South Timbalier 151 for supporting this study. S. Keenan kindly helped with the field sampling. We gratefully acknowledge W. T. Peterson, M. Dagg, R. Shaw, and R. Downer for valuable advice that markedly improved the quality of this paper. We are indebted to 2 anonymous referees for their valuable comments and to E. Durbin for insightful discussion.

\section{LITERATURE CITED}

Aksnes DL, Magnesen T (1983) Distribution, development, and production of Calanus finmarchicus (Gunnerus) in Lindåspollene, western Norway, 1979. Sarsia 68:195-208

- Aksnes DL, Ohman MD (1996) A vertical life table approach to zooplankton mortality estimation. Limnol Oceanogr 41: 1461-1469

Aksnes DL, Miller CB, Ohman MD, Wood SN (1997) Estimation techniques used in studies of copepod population dynamics - a review of underlying assumptions. Sarsia 82:279-296

Bi H (2005) Population dynamics of Clausocalanus furcatus (Copepoda, Calanoida) in the northern Gulf of Mexico. $\mathrm{PhD}$ dissertation, Louisiana State University, Baton Rouge

Bi H, Benfield MC (2006) Egg production rates and stage-specific development times of Clausocalanus furcatus (Copepoda, Calanoida) in the northern Gulf of Mexico. J Plankton Res 28:1199-1216

Bowman TE (1971) The distribution of calanoid copepods off the southern United States between Cape Hatteras and southern Florida. Smithson Contrib Zool 96:1-58

Carlotti F, Gikse J, Werners F (2000) Modeling zooplankton dynamics. In: Harris RP, Wiebe PH, Lenz J, Skjoldal HR, Huntley M (eds) ICES Zooplankton Methodology Manual. Academic Press, San Diego, CA, p 571-667

Caswell H (2001) Matrix population models: construction, analysis, and interpretation. Sinauer Associates, Sunderland, MA

Caswell H, Twombly S (1989) Estimation of stage-specific demographic parameters for zooplankton populations: methods based on stage-classified matrix population models. In: McDonald L, Manly B, Lockwood J, Logan J (eds) Symposium on estimation and analysis of insect populations. Springer-Verlag, Berlin, p 93-107

Cornils A (2005) Seasonal dynamics of the copepod population in an oligotrophic environment - the Gulf of Aqaba (Red Sea). PhD dissertation, University of Bremen

Dagg MJ, Whitledge TE (1991) Concentration of copepod nauplii associated with the nutrient-rich plume of the Mississippi River. Cont Shelf Res 11:1409-1423

Eiane K, Ohman MD (2004) Stage-specific mortality of Calanus finmarchicus, Pseudocalanus elongatus and Oithona similis on Fladen Ground, North Sea, during a spring bloom. Mar Ecol Prog Ser 268:183-193

Eiane K, Aksnes DL, Ohman MD, Wood D, Martinussen MB (2002) Stage-specific mortality of Calanus spp. under different predation regimes. Limnol Oceanogr 47:636-645

Frost B, Fleminger A (1968) A revision of the genus Clausocalanus (Copepoda: Calanoida) with remarks on distributional patterns in diagnostic characters. Bull Scripps Inst Oceanogr Univ Calif 12:1-235

Gehrs WC, Roberston A (1975) Use of life tables in analyzing the dynamics of copepod populations. Ecology 56:665-672

Gilioli G, Pasquali S (2007) Use of individual-based models for population parameters estimation. Ecol Modell 200: 109-118 
Hairston NG, Twombly S (1985) Obtaining life table data from cohort analysis: a critique of current methods. Limnol Oceanogr 30:886-893

Herman AW, Sameoto DD, Shunnian C, Mitchell MR, Petrie B, Cochrane N (1991) Sources of zooplankton on the Nova Scotia Shelf and their aggregation with deep shelf basins. Cont Shelf Res 11:211-238

Hiby AR, Mullen AJ (1980) Simultaneous determination of fluctuating age structure and mortality from field data. Theor Popul Biol 18:192-203

Hirst AG, Kiørboe T (2002) Mortality in marine planktonic copepods: global rates and patterns. Mar Ecol Prog Ser 230:195-209

> Hirst AG, Bonnet D, Harris RP (2007) Seasonal dynamics and mortality rates of Calanus helgolandicus over two years at a station in the English Channel. Mar Ecol Prog Ser 340: 189-205

Huntley ME, Niiler PP (1995) Physical control of population dynamics in the Southern Ocean. ICES J Mar Sci 52:457-468

Ianora A, Poulet SA (1993) Egg viability in the copepod Temora stylifera. Limnol Oceanogr 38:1615-1626

Ianora A, Mazzocchi MG, Grottoli R (1992) Seasonal fluctuations in fecundity and hatching success in the planktonic copepod Centropages typicus. J Plankton Res 14: 1483-1494

Keenan SF (2002) The importance of zooplankton in the diets of blue runner (Caranx crysos) near offshore petroleum platforms in the northern Gulf of Mexico. MSc dissertation, Louisiana State University, Baton Rouge

> Kiørboe T (1997) Population regulation and role of mesozooplankton in shaping marine pelagic food webs. Hydrobiologia 363:13-27

Kleppel GS, Burkart CA, Houchin L (1998) Nutrition and the regulation of egg production in the calanoid copepod Acartia tonsa. Limnol Oceanogr 43:1000-1007

Lester KM, Heil CA, Neely MB, Spence DN and others (2008) Zooplankton and Karenia brevis in the Gulf of Mexico. Cont Shelf Res 28:99-111

Li X, Mcgillicuddy JDJ, Durbin EG, Wiebe PH (2006) Biological control of the vernal population increase of Calanus finmarchicus on Georges Bank. Deep Sea Res II 53:2632-2655

Liang D, Uye S (1997) Population dynamics and production of the planktonic copepods in a eutrophic inlet of the Inland Sea of Japan. IV. Pseudodiaptomus marinus, the eggcarrying calanoid. Mar Biol 128:415-421

> Longhurst AR (1985) The structure and evolution of plankton communities. Prog Oceanogr 15:1-35

Love MS, Caselle J, Snook L (1999) Fish assemblages on mussel mounds surrounding seven oil platforms in the Santa Barbara Channel and Santa Maria Basin. Bull Mar Sci 65: 497-513

Manly BF (1990) Stage-structured populations: sampling, analysis, and simulation. Chapman \& Hall, London

Marum JP (1974) Spatial and temporal variations of zooplankton in relation to offshore oil drilling and estuarine marine faunal exchange. PhD dissertation, Florida State University, Tallahassee

Mazzocchi MG, Paffenhöfer GA (1998) First observations on the biology of Clausocalanus furcatus (Copepoda, Calanoida). J Plankton Res 20:331-342

McCauley E, Murdoch WW (1990) Predator prey dynamics in environments rich and poor in nutrients. Nature 343: $455-457$

Miller CB, Judkins DC (1981) Design of pumping systems for sampling zooplankton, with descriptions of two high-capacity samplers for coastal studies. Biol Oceanogr 1:29-56

Minello TJ (1980) The neritic zooplankton of the northwest- ern Gulf of Mexico. PhD dissertation, Texas A\&M University, College Station

Mullin MM (1991) Relative variability of reproduction and mortality in two pelagic copepod populations. J Plankton Res 13:1381-1387

Nelson WA, McCauley E, Wimbert J (2004) Capturing dynamics with the correct rates: inverse problems using semiparametric approaches. Ecology 85:889-903

> Ohman MD (1986) Predator limited population growth of the copepod Pseudocalanus sp. J Plankton Res 8:673-713

Ohman MD, Hirche HJ (2001) Density-dependent mortality in an oceanic copepod population. Nature 412:638-641

> Ohman MD, Wood SN (1996) Mortality estimation for planktonic copepods: Pseudocalanus newmani in a temperate fjord. Limnol Oceanogr 41:126-135

> Ohman MD, Runge JA, Durbin EG, Field DB, Nieho B (2002) On birth and death in the sea. Hydrobiologia 480:55-68

> Ohman MD, Eiane K, Durbin EG, Runge JA, Hirche HJ (2004) A comparative study of Calanus finmarchicus mortality patterns at five localities in the North Atlantic. ICES J Mar Sci 61:687-697

> Ortner PB, Hill LC, Cummings SR (1989) Zooplankton community structure and copepod species composition in the northern Gulf of Mexico. Cont Shelf Res 9:387-402

> Paffenhöfer GA (2002) An assessment of the effects of diatoms on planktonic copepods. Mar Ecol Prog Ser 227:305-310

> Peterson WT, Kimmerer WJ (1994) Processes controlling recruitment of the marine calanoid copepod Temora longicornis in Long Island Sound: egg production, egg mortality, and cohort survival rates. Limnol Oceanogr 39:1594-1605

Rigler FH, Cooley JM (1974) The use of field data to derive population statistics of multivoltine copepods. Limnol Oceanogr 19:636-655

Rountree RA (1990) Community structure of fishes attracted to shallow-water fish aggregation devices off South Carolina, USA. Environ Biol Fishes 29:241-262

Stanley DR, Wilson CA (1990) A fishery-dependent based study of fish species composition and associate catch rates around oil and gas structures off Louisiana. Fish Bull 88: 719-730

> Steele JH, Henderson EW (1995) Predation control of plankton demography. ICES J Mar Sci 52:565-573

> Tarling GA, Shreeve RS, Ward P, Atkinson A, Hirst AG (2004) Life cycle phenotypic composition and mortality of Calanoides acutus (Copepoda: Calanoida) in the Scotia Sea: a modeling approach. Mar Ecol Prog Ser 272:165-181

> Torres-Sorando LJ, Zacarias D, de Roa EZ, Rodríguez DJ (2003) Population dynamics of Oithona hebes (Copepoda: Cyclopoida) in a coastal estuarine lagoon of Venezuela: a stage-dependent matrix growth model. Ecol Modell 161: $157-166$

Twombly S (1994) Comparative demography and population dynamics of two coexisting copepods in a Venezuelan floodplain lake. Limnol Oceanogr 39:234-247

> Twombly S, Lewis WM Jr (1989) Factors regulating cladoceran dynamics in a Venezuelan floodplain lake. J Plankton Res 11:317-333

Vervoort W (1963) Pelagic copepoda. Part I. Copepoda Calanoida of the families Calanidae up to and including Euchaetidae. Atlantide Rep 7:77-194

- Wiebe PH (1970) Small-scale spatial distribution in oceanic zooplankton. Limnol Oceanogr 15:205-217

> Wood SN (1994) Obtaining birth and mortality patterns from structured population trajectories. Ecol Monogr 64:23-44

Wood SN, Nisbet RM (1991) Estimation of mortality rates in stage-structured populations. Lecture Notes in biomathematics, 90. Springer Verlag, p 1-101 